\title{
Medical practice in the technological age
}

The $20^{\text {th }}$ century has witnessed many events: some shocking the world, like the two World Wars and their dramatic consequences; others beneficial to humanity, advancing throughout the years. Amongst several developments, advances in the sciences have notably stood out and astonished the world like never before.

Those advances have occurred in all sciences and have greatly impacted the work of myriad disciplines. Standouts include medical sciences that from the end of the $19^{\text {th }}$ century to the beginning of the $20^{\text {th }}$ century improved health care for the population.

The progress of science has followed its usual path, which is characterized by the remarkable effort and commitment of many researchers who have dedicated much of their lives to this arduous task. Even with very limited resources, great people have left humanity with enormous benefits through admirable discoveries, including Pasteur, Koch, Fleming, among many others. Likewise, in Argentina, we have had exceptional examples of medical research, such as the universally renowned Houssay, Braun Menendez, Leloir, and Milstein.

However, the world was changing markedly by the end of World War II and that had an impact on every aspect of our lives, including medicine. Scientific progress became increasingly more important, but it was not alone: the overwhelming and continuous development of technology was by its side.

Certainly, there are more brilliant scientists and more science than at any other time, but it is also true that there have never been some many problems and decline in health care, derived, in my opinion, from the negative influence of the dark side of technology, in addition to the persistent commoditization of medicine.

Undoubtedly the development of technology has been, and still is, of enormous importance and is very present in the multiple and impressive achievements of medicine. Therefore, it is necessary to understand that criticisms are mostly due to an inappropriate use and not to the technology itself. Unfortunately, this action has generated much damage to and a decline in the medical profession and, consequently, patient care.

Karl Jaspers, a philosopher and physician, confirmed this 50 years ago: "In modern medicine, everything seems to be in the best of order. Each day, great results are achieved for many patients. But the amazing thing is that, for patients and doctors, dissatisfaction increases." 1

Several aspects are at stake with the decline in medical practice occurring in the technological era, especially the changes in the attitudes of physicians towards their patients, which are significantly different from the ethical attributes that govern our profession.

"Bedside manner" or a pleasant consultation, where the doctor was unhurried and empathetic, thus getting to know the patient as much in his or her sufferings as his or her desires, were transformed into something subject to technological "successes" and commercialism. This resulted in more insensitive physicians, wherein little by little we began to accept less and less time in consultation, and the fact that because of market ambition we were losing our dignity.

How has the inadequate use of technology contributed to the frank deterioration of health care? Many factors are involved in this process, but I will only list those that I believe are the most significant in terms of deterioration of our profession.

Sociological changes in the technological age have diluted the "character" of physicians, who submit to technology instead of controlling it based on the supposition that it leads to a "more precise" medicine; in reality, it is the exact opposite and is dominated by uncertainty. The belief that technology is a "magic potion" causes it to be misused and, gradually, physicians are harassed by external factors and become technicians, thus losing their medical ideals. The biggest problem is that not only are the scientific aspects lost, but also the humanistic ones; this way, physicians, faced with the avalanche of new techniques and their inadequate use, will progressively become indifferent and "estranged" from their patients.

Without a doubt, the inadequate use of diagnostic methods accounts for most of technology misuse, which is due, among other reasons, to the shorter time in medical consultation, not listening to the patient, believing that with technology we are moving towards better and "more modern" medicine, and to the increasing commoditization that has "invaded" medicine. Regarding the attitude of not listening to patients, Willian Osler gave us this memorable quote: "Listen to your patient, he is telling you the 
diagnosis," a message that, in my opinion, should always be present in our practice.

The assumption that technology is good because it is modern has no support and is really a fallacy. Those who believe this do not take into account that in order to correctly define that any given technology is modern, it is imperative that its objectives are focused on the needs of the people, and not on the modernity of its procedures.

Additionally, one of the biggest criticisms today is the conviction of many professionals that the only thing of interest in technological development is to achieve a tireless and lucrative phenomenon. This is unacceptable behavior in patient care and is therefore morally inadmissible. Likewise, excessive profit -added to the enormous amount of unnecessary tests- results in a marked increase in the costs of care, an extremely serious problem in current medicine.

Another aspect to note is that incessant technological development makes physicians increasingly subjected to that process, something that, with current extensive medicalization, produces a false illusion in people that, through technology, medicine will solve all of their problems.

Anatole Broyard, a prominent American critic and writer related in his posthumous book, Intoxicated By My Illness, how he felt -as a terminal patient- when faced with illness, including some of the aspects we have addressed above: "The mechanics of diagnosis are mostly done, in my ignorant opinion, by technicians. The technicians bring in the raw material. The doctor puts them into a poem of diagnosis. So I want a doctor with a sensibility. To the typical physician, my illness is a routine incident in his rounds, while for me it's the crisis of my life. I would feel better if I had a doctor who at least perceived this incongruity." 2

In my view, in the presence of inadequate attitudes, either because of interests or ignorance and from those only seeking profit, we are in an age where many honest doctors become powerless and therefore do not fight to bring about change that leads to the avoidance of dangers of technology misuse.

There is no doubt that technology will continue its course and reap many more benefits, but at the same time, if our indifference persists, the current problems will continue and patients will be harmed. As we cannot morally avoid technological progress, physicians must monitor and control "its potential success" and prevent its inappropriate use.

To conclude, here are some thoughts that may help us reflect on behavior in our profession. The Hastings Center in New York, a worldrenowned bioethics institute, published The Goals of Medicine 20 years ago. ${ }^{3}$ Below is an excerpt:

"An Honorable Medicine, Directing Its Own Professional Life"

"Medicine should listen to what societies want from it and try to be as responsive as possible. Medicine must have its own vital inner life [...] and chart its own course in partnership with society [and in defense of patients]. But that way can be found if medicine begins with its own history and traditions and continually returns to its original impetus: the relief of suffering and the pursuit of health."

José María Ceriani Cernadas

Editor

http:/ /dx.doi.org/10.5546/aap.2017.eng.106

To cite: Ceriani Cernadas JM. Medical practice in the technological age. Arch Argent Pediatr 2017;115(2):106-107.

\section{REFERENCES}

1. Jaspers J. La práctica médica en la era tecnológica. Barcelona: Gedisa; 1988.

2. Broyard A. Ebrio de enfermedad. Segovia: La uña rota; 1991.

3. Las metas de la medicina. "Mirando hacia adelante". The Hasting Center Report 1996. 